\title{
Establishment of emotional database and extraction of color psychology of children from images
}

\author{
Seong-Yoon Shin \\ School of Computer Information \& Communication Engineering, Kunsan National University, \\ 558 Daehak-ro, Gunsan-si, Jeollabuk-do (Miryong-dong), South Korea
}

\begin{tabular}{l} 
Article Info \\
\hline Article history: \\
Received Sep 8, 2018 \\
Revised Nov 9, 2018 \\
Accepted Nov 19, 2018 \\
\hline
\end{tabular}

Keywords:

Color image space Color psychology

Emotional database

K-mean clustering

Sensibility

\begin{abstract}
In the modern society, there is a rapid increase in the need for color psychotherapy for psychological stability and environmental adaption of children for whom the interests of the parents are lacking in the midst of their busy daily schedules. Accordingly, we need to assess the emotional state of children through their drawings, etc. In this thesis, identification is made on color harmony by utilizing information of single and mixed colors in the color image space. Moreover, system for extraction of color psychology from the drawings of children is developed. First, emotional database is established on the basis of color image space. Then, enormous color values are group by clustering the images through the use of K-Means clustering. Emotions are extracted through matching with the database and child's color psychology is examined by using color distribution chart. Empirical researches on sensibilities that are currently in progress are being pursued largely from psychological and engineering perspectives. Sensibility being understood in the area of psychology can be deemed close to being emotions. Meanwhile, sensibility understood from the engineering perspective can be defined as highly advanced psychological experiences induced in the minds of human beings from perception or cognition by external physical stimulation. This thesis demonstrated the overall excellence through experiment.
\end{abstract}

Copyright $\odot 2019$ Institute of Advanced Engineering and Science. All rights reserved.

\section{Corresponding Author:}

Seong-Yoon Shin,

School of Computer Information \& Communication Engineering,

Kunsan National University,

558 Daehak-ro, Gunsan-si, Jeollabuk-do (Miryong-dong), South Korea.

Email: s3397220@kunsan.ac.kr

\section{INTRODUCTION}

Color has the power to influence the physiology or emotions of human beings. This is because mankind not only views colors through the eyes but also moves mind and emotion by accommodating the colors with their hearts. Emotional expressions after having looked at colors display differing responses depending on individuals. As such, colors move our minds through emotional action and lead us to think and act unconsciously as well as act differently in accordance with the extent of sensibility of individuals.

Generally, people have tendency of selecting the colors they like unconsciously rather than making choices by pondering over the characteristics, advantages and disadvantages that each of the colors has. Such tendency is particularly more prominent in children with lack of knowledge or experiences on the characteristics of colors. This is influenced compositely by the psychological state at the time, individual propensity and environmental characteristics, etc. [1].

Children talk about their sentiments, personality, internal desires, concepts, and expressions and environment of their daily life experiences through drawings and colors instead of their verbal languages. Accordingly, this thesis will extract color-specific information from the drawing that children personally 
drew to assess their emotional state on such colors. Empirical studies on sensibilities that are being carried out at the moment are being pursued largely from psychological and engineering perspectives. Sensibilities understood in the area of psychology can be seen as being close to emotion and, generally, 'sensibility or sentiment is being used in its superordinate concept that includes various emotions and is being defined with focus on relative psychological domain'. On the other hand, sensibility understood from engineering perspective is being understood under the 'definition of composite emotions of sense of comfort and luxuriousness as highly advanced psychological experiences induced within the human beings arising from perceptions and cognition of external physical stimulations'. Among these sensibilities, database will be established for those on colors. However, the attributes that colors have are extremely broad and there is difficulty in generalizing the responses of individuals. In order to resolve this difficulty, considerations will be made comprehensively on the understanding of the attributes of colors as well as the psychological symbols and effects through the functions of the colors that are absorbed as one of our daily life effects. In addition, sensibilities towards colors will be investigated by selecting specific subjects and database will be established on the basis of this investigation. Then, sensibilities will be extracted from images and the color psychology of children will be assessed to enhance the psychological stability and environmental adaption capabilities of children.

\section{RELATED RESEARCH}

\subsection{Psychological Actions on Colors}

Whether we are aware or not, colors govern our mental and psychological states. Colors have various properties. Colors have various symbolic meanings including provocative or pacifying and sense of weight, etc. There are occasions in which one become fatigued or feel subdued due to the effects of colors without being aware.

Colors in themselves have the power to impart substantial influence on people as well as in combination with various configurations. Color psychology is aimed at researching the changes in human beings induced by such actions of colors [2]. Psychological effects of colors include the aspects that are decided in advance in order to establish visual ambience including image association, impression and characteristics of colors, et. Configurations of colors not only impart influence on the visual sensory organs, that is, eyes, diversely but also influence emotion and sentiments with vision as the medium. Perception of colors can be approached from psychological method since it exists in our minds. Investigation of the personal preferences on particular color can assist with understanding of the effects including emotion and sentimental responses toward colors, etc. [3]. Table 1 illustrates how Faber Biren defined the psychological actions of key colors. This illustrates that psychological action on the colors is important. Table 2 illustrates the impressions of colors that are illustrated in the relationship between colors and configurations.

Table 1. Psychological Actions of Key Colors

\begin{tabular}{cc}
\hline Colors & Psychological actions \\
\hline Red & Increase in anxiety and tension \\
Orange & Enhancement of appetite \\
Yellow & Refreshing and brilliant feeling \\
Green & Peace of mind \\
Blue & Comfort \\
Purple & Emotionally neutral \\
\hline White & Sense of balance \\
Black & Negative feeling \\
Grey & Passive feeling \\
\hline
\end{tabular}

Table 2. Relationship between Color and Configurations

\begin{tabular}{|c|c|c|}
\hline Color & Configuration & Impressions of color \\
\hline Red & Rectangle and hexagon & Feeling of hot, dry and opacity \\
\hline Orange & Forward & It is less erotic color than red with addition of the feeling of white heat. \\
\hline Yellow & $\begin{array}{l}\text { Inverted triangle and pyramid } \\
\text { shape }\end{array}$ & $\begin{array}{l}\text { Spiritual feeling } \\
\text { Lacks sense of texture and weight }\end{array}$ \\
\hline Green & Hexagon and icosahedron & Cool, fresh and soft \\
\hline Blue & Circle, sphere & $\begin{array}{l}\text { Cold, moist and transparent } \\
\text { Spiritual feeling }\end{array}$ \\
\hline Purple & Egg shape & Gentle and flowing feeling \\
\hline
\end{tabular}




\subsection{Child's Color Psychology}

Experiences of children tend to be limited and they easily display immediate and emotional responses in comparison to adults. That is, they think and act within the boundaries of their limited experiences. Therefore, environment given to children impart enormous effects on the growth of children [4].

Although there are many theses written on the color psychology of children, only a few will be introduced here. K.B. Kim executed dominant color analysis on the drawings by children and grouped the color information by applying ART2 algorithm. He then fuzzified by applying the color frequency number to membership function on the basis of the core vector value of each that has been grouped. Defuzzification was then executed after having applied the fuzzified core vector value to the fuzzy inference rules in order to compare the psychological state of colors [5].

H.H. Park, by utilizing the color concept approached by means of color sensibilities and symbols educationally, developed and established foundation for lesson proposal for color classes of children's arts. In particular, he established the proposal for teaching arts classes by making reference to the results of analysis of image scale of existing IRI adjectives for the analysis of the means of utilization of color psychology in education [6].

S.J. Jeong investigated the effects on the color preferences by assessing the factor structure of lifestyle of children and disclosing the relationship with the color preferences in accordance with the lifestyle of children $[7,8]$.

Grandgeorge $\mathrm{M}$ and Makataka $\mathrm{N}$ identified colors that display color-hypersensitive response characteristics by investigating the color preferences of children with autism spectrum disorder (ASD) and ordinary children [9].

\section{ESTABLISHMENT OF SENSITIBILITIES DB}

Johannes Itten studied the mixing methods of color and the contrasting effects of colors. It is characterized by the attempt to make expressions through geometric contrast of color, regular arrangement of colors and contract of colors with sense of seasons. The theory of harmony of Itten illustrates the method of selecting colors for expression of themes and functional characteristics in accordance with such method [10].

1. Dyads - Harmony is achieved if mixed with complementary colors.

2. Split complementary - Neighboring complementary colors are used mostly. Harmony is achieved if mixed with colors near the complementary colors on both sides.

3. Triad - Harmony is achieved if colors at the position of 3 equal divisions of the color wheel.

4. Tetrads - Harmony is achieved if colors at the position of 4 equal divisions of the color wheel, and fundamentally, the mixing of color that align with the 2 set of complementary colors also achieve harmony.

5. Pentads - Harmony is achieved if colors at the position of 5 equal divisions of the color wheel or through 5-color mixing by adding white and black to Triad.

6. Hexads - Harmony is achieved if colors at the position of 6 equal divisions of the color wheel, or 6color mixing by 3 sets of complementary colors or by adding white and black to Tetrads.

Methods of 12-color wheel and color-mixing method of Itten for establishment of sensibilities DB are illustrated in the Figure 1.

Colors are essential elements in the world of graphic design and advertisement. They not only illustrate depth and emphasis but also deliver the feeling and emotion of design. Graphic design creates beautiful layout and fantastic designs. In fact, it can be seen as a part of psychology. Colors are one of the tools used to connect with people as illustrated above. Colors provide arrangement of emotional and visual signals. Display of emotions that people experience about colors is illustrated in the Table 3. 


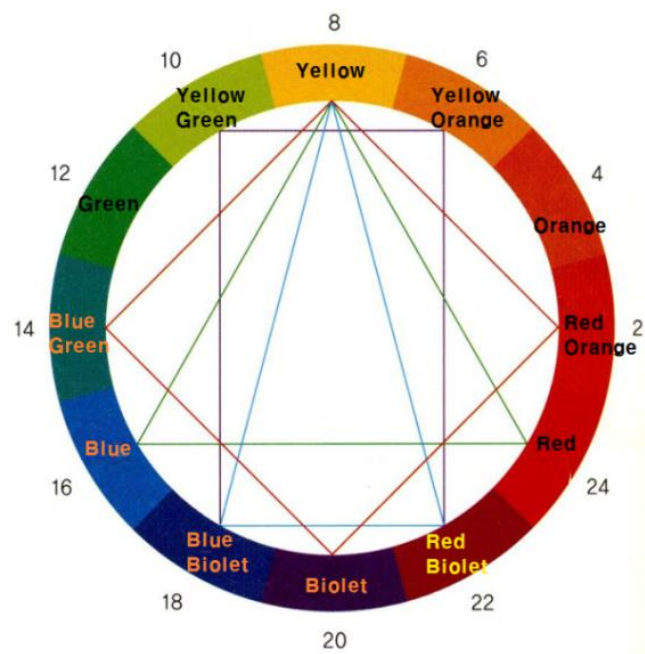

Figure 1. 12-color wheel of itten

Table 3. Meanings Contained in Colors

\begin{tabular}{|c|c|}
\hline Colors & Meanings Contained in Colors \\
\hline Grey & Anxiety, expectations, wariness and feeling of inferiority \\
\hline Black & Invisible, emptiness (fear), potential and possibilities, suppression of emotion \\
\hline White & $\begin{array}{c}\text { Transparency of spirit, thoroughly cleaned, purification of thoughts or actions, new } \\
\text { beginning }\end{array}$ \\
\hline Orange & Promotion of activities, strong appetite, promotion of socialization \\
\hline Red & $\begin{array}{l}\text { Elevate passion, vitality, blood pressure, breathing, heartbeat and pulse rates } \\
\text { Enhancement of action and confidence, provide sense of protection against fear, } \\
\text { concerns and worries }\end{array}$ \\
\hline Orange & $\begin{array}{l}\text { Induces vitality, and elevates blood pressure, breathing and heartbeat } \\
\text { Enhancement of action and confidence, focuses on imagination rather than action }\end{array}$ \\
\hline Reddish brown & Material greed, appetite and degeneration \\
\hline Yellow & $\begin{array}{c}\text { Promote mental growth and nerves, improve memory, desire for affection, } \\
\text { degeneration }\end{array}$ \\
\hline Green & $\begin{array}{l}\text { Pacification and alleviation of tension, alleviation of depression and concerns, ability } \\
\text { to recover, lack of self-control, harmony, fatigue and submission }\end{array}$ \\
\hline Blue & $\begin{array}{c}\text { Calmness and pacification, coldness, intuition, high expectation of parents, suppress } \\
\text { and obedient }\end{array}$ \\
\hline Purple & $\begin{array}{l}\text { Hope and spirituality, calms the mind and nerves, promote creativity and poor } \\
\text { interpersonal relationship }\end{array}$ \\
\hline
\end{tabular}

Attributes of colors are extremely broad and it is difficult to generalize the responses of individuals. In order to resolve this problem, it is necessary to comprehensively consider the functions of the color and the ensuing psychological symbols and effects. In this thesis, sensibilities database is established by means of the 12-color wheel of Itten, I.R.I adjective image scale and the meaning that colors have.

\section{EXTRCTION OF COLOR PSYCHOLOGY OF CHILDREN}

\subsection{K-means Clustering}

K-Means clustering algorithm is one of the simplest and fastest cluster algorithms. Fundamental method is to repetitively find the center of cluster (centroid) $\mu \mathrm{k}$ and the cluster to which each data will be affiliated with until the target function value is minimized as illustrated below. This value is referred at as inertia.

$$
J=\sum_{k=1}^{K} \sum_{i \in C_{k}} d\left(x_{i}, \mu_{k}\right)
$$

In this equation, $\mathrm{d}$ is the dissimilarity of distance between the 2 data and is defined as follows: 


$$
d\left(x_{i}, \mu_{k}\right)=\left\|x_{i}-\mu_{k}\right\|^{2}
$$

Detailed algorithm is as follows:

a) Choose arbitrary centroid, $\mu \mathrm{k}$. (Usually, select one of the data samples)

b) Compute the distance from the centroid to each sample data

c) Renew the cluster by selecting the centroid that is nearest to each data sample

d) Compute the centroid for the cluster that has been created again and repeat the above process of a d.

Setting the number or initial core value of $\mathrm{K}$ is the most important issue of this algorithm and there is no change in the conclusion that the processing time decreases if the $\mathrm{K}$ is made as small as possible. There are numerous algorithms that reduce the number of $\mathrm{K}$ and determine the core pixel. Among these, the method of determining the number of $\mathrm{K}$ and the core pixel by dividing the RGB color space into 8 sections was employed.

\subsection{Labeling}

Labeling signifies the work for assigning unique number to particular pixel cluster in image processing. Number is allocated to each group in order to match the clustered resultant image with the sensibilities database. When labeling, the label numbers that correspond to the color range in the sensibilities database will be assigned.

\subsection{Extraction of Psychology of Children}

Explaining research For the image with inputted query, pixels with the same color characteristics were clustered by using the K-means algorithm. When clustering, clusters with $0.1 \%$ understanding portion of the overall pixel number were excluded. In addition, each of the clusters was assigned with number for matching with database and extraction.

Experiment was executed on 8-year old girl to extract color psychology of children. This child has regular religious activity of attending church services on every Sundays and conscientiously pursuing her personal affairs. She has relatively cheerful personality and adapts well to her surrounding very well along with the tendency of fulfilling her responsibilities. However, she has introverted personality of not being able to express her emotions. She draws picture by extensively using colors in blue range in overall.

After having extracted color-specific information by using clustering by inputting this drawing as query image, it was matched with the sensibilities database of the child on colors.

\section{EXPERIMENTS}

This thesis was materialized with Visual C++ 2015, and sensibilities DB was established with MsSQL Server 2016. Picture drawn by an 8-year old girl was used as the experimental data, as aforementioned.

The Figure 2 illustrates extraction of sensibility from nature image. In the Figure 2, the $1^{\text {st }}$ image is the original image while the $2^{\text {nd }}$ image is the clustered image. Although 5 clusters were extracted here, 3 sensibilities in accordance with the colors were extracted. Colors with percentages of less than $12 \%$ in the cluster were excluded.

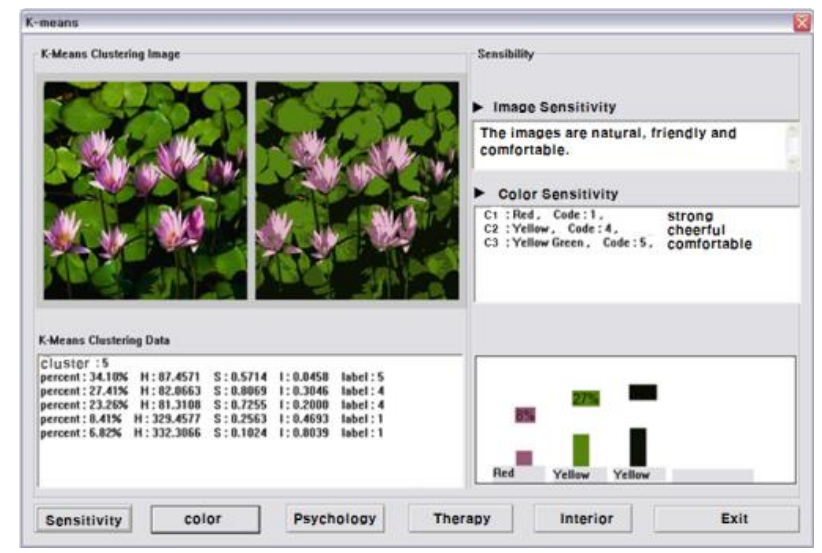

Figure 2. Extraction of sensibilities from nature image 
Figure 3 illustrates extraction of color psychology from the drawing by the 8-year old girl who is the subject of the experiment. Here, 3 clusters were extracted. The extracted cluster was matched with sensibility DB for extraction of color psychology of the child.

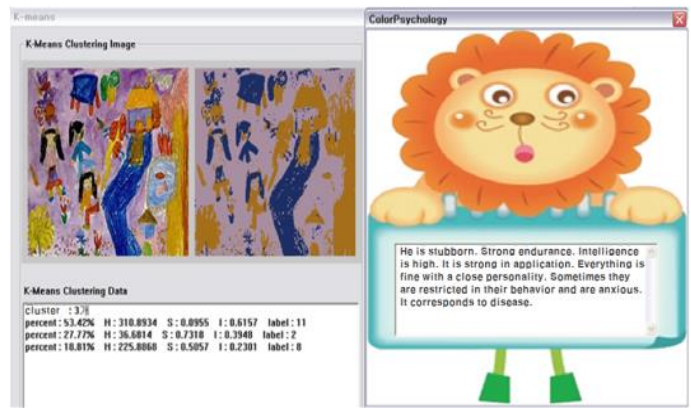

Figure 3. Extraction 1 of color psychology from the drawing by the child

Figure 4 illustrates the images of extraction of sensibilities from the drawings by the child. The figure illustrates image of picture completed by drawing desk in the middle. Although 4 clusters were detected in this image, those with percentage below $12 \%$ were excluded unconditionally regardless of the number of labels.

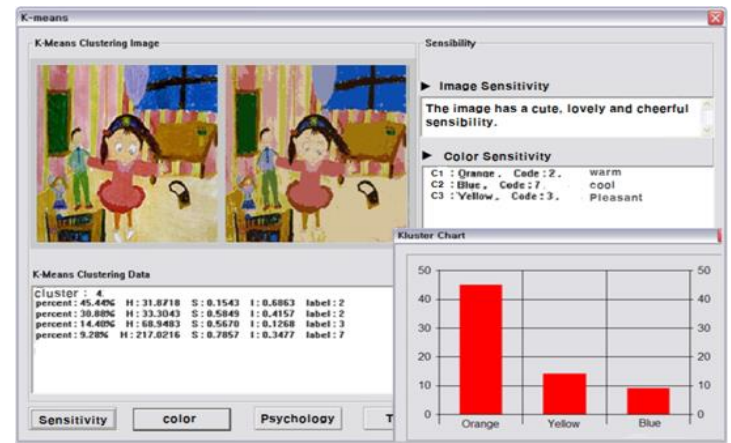

Figure 4. Extraction of sensibilities from the drawing by the child

Figure 5 illustrates the image of extraction of color psychology from the drawing by the child. As it can be seen in the Figure, it is drawing before the child drew desk in the middle and the color of the wall is substantially darker. Although 8 clusters were detected in this image, those with percentage below $12 \%$ were excluded unconditionally. As the result, 3 clusters, namely, Orange, Blue and Yellow were detected.

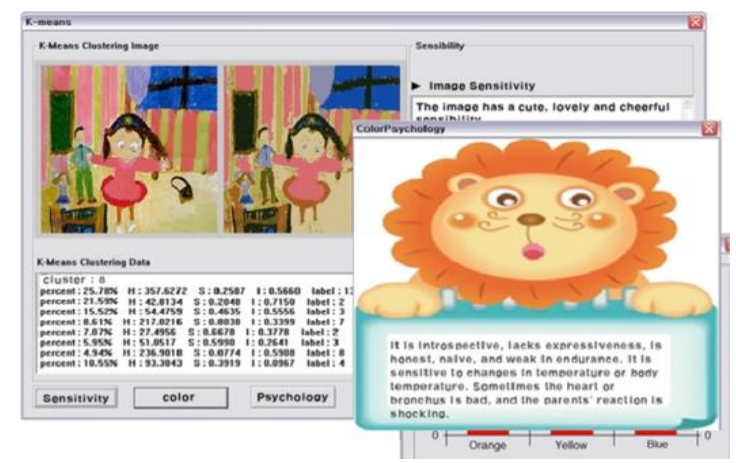

Figure 5. Extraction 2 of color psychology from the drawing of the child 
Resultantly, although Figure 4 and Figure 5 have images that are slightly different, it is evident that there is no significant difference in the desks that the children wanted to express.

As the result of having executed experiments such as above more than 100 times, it was possible to deduce the following results of performance evaluation of the system as follows:

a) This thesis used 12-color wheel of Itten.

b) Sensibilities cognition and DB establishment was executed through IRI adjectives of image space.

c) Color psychology was extracted in accordance with the objective data of scholars.

\section{CONCLUSION}

In this thesis, color harmony was identified by using the color mixing information in the color image space. For color harmony, colors that achieve harmony with each other in the 12-color wheel of Itten were extracted. In addition, sensibility DB was established on the basis of 12-color wheel and results of color recognition on the child by researchers. Through this, system for extraction of the color psychology from the pictures drawn by child was developed. First, enormously broad color values are grouped in the drawing images of the children by using K-Means clustering. Then, appropriate sensibilities are extracted through matching with sensibilities database and child's color psychology was examined by using color distribution chart. In addition, it was proven through experiment that the system introduced in this thesis is superior over other system.

\section{REFERENCES}

[1] D. S. HAN, "Color test card for children's propensity analysis, " KR101197025B1(Korea Patents). 2009.

[2] S. R. Lee, "Study on the Method of Color Psychology using The comic dual and Five element, "Journal of Korean Society of Color Design Studies, Vol. 1, No. 1, pp. 129-136, 2005.

[3] Y. M. Song, "A study on the influence of environmental color on the leisure and welfare facility for the old, " Thesis of Master. Graduate School of Industrial Arts. Hong-ik University, 2009.

[4] H. A, Kim, "Mandala coloring activities for children with emotional disorders seen, color psychology, " Master's Thesis in Graduate School Young-nam University, 2009.

[5] K. B. Kim, "Reading Children's Mind from Digital Drawings based on Dominant Color Analysis using ART2 Clustering and Fuzzy Logic, " Journal of KIICE, Vol. 20, No. 6, pp. 1203-1208, 2016.

[6] H. H. Park, "A Study on the Guidance of Children`s Art through Sensibility and Symbol of Color -Focusing on IRI Image Scale Color Sensibility Scale-," Bulletin of Korean Society of Basic Design \& Art, Vol. 18, No. 3, [[. 139-151, 2017.

[7] S. J, Jeong, "A Basic Study on Color Preference of Children: Focused on the Properties of Colors, " Journal of KSCS, Vol. 30, No. 4, pp. 55-63, 2016.

[8] S. J. Jeong, "The Effect of Color Preference Depending on the Lifestyle of Children, " Korean journal of arts education, Vol. 14, No. 4, pp. 81-96, 2016.

[9] Grandgeorge M and Masataka N, "Atypical Color Preference in Children with Autism Spectrum Disorder, " Frontiers in Psychology 2016, Vol. 7(Article 1976), pp. 1-5, 2016.

[10] Itten, J. and Birren, F., "The elements of color, " NY. USA: John Wiley \& Sons Ltd, 1970.

\section{BIOGRAPHIES OF AUTHORS}

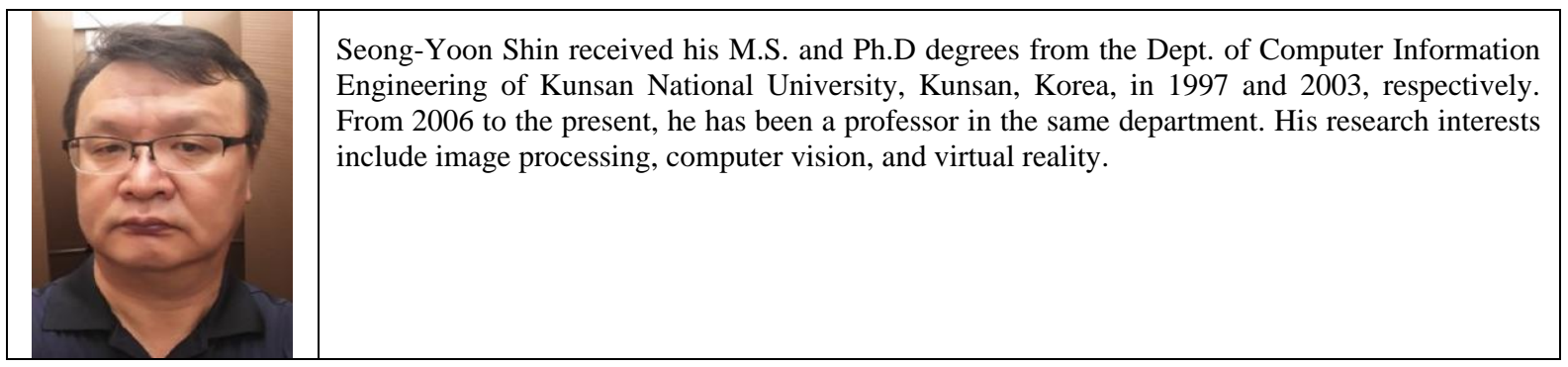

